REVISTA DE LA CEPAL 82 . ABRIL 2004

\title{
Migraciones, mercado de trabajo y pobreza en el Gran Buenos Aires
}

\author{
Rosalia Cortés y Fernando Groisman
}

Rosalía Cortés

Profesora Investigadora

•r rcortes@fibertel.com.ar

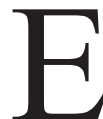

ste trabajo analiza el comportamiento laboral de dos segmentos de migrantes -uno, proveniente de las provincias argentinas y el otro de países limítrofes- en el Gran Buenos Aires durante el decenio de 1990. Sus trayectorias laborales difirieron: aumentó la actividad económica de los migrantes limítrofes y se extendió el "no trabajo" de los migrantes internos. Operó un proceso de sustitución de migrantes internos por limítrofes: éstos permanecieron en ocupaciones precarias y mal remuneradas, mientras que los internos engrosaron el contingente de "pobres estructurales", sin ocupación, con inserción laboral ocasional, y con pocas posibilidades de mejorar su situación en un futuro cercano.

Fernando Groisman

Investigador Invitado

œ fgroisman@tutopia.com

Facultad Latinoamericana

de Ciencias Sociales

(Área Economía y Tecnología)

y Consejo Nacional de Investigaciones Científicas y Técnicas (FLACSOCONICET), Argentina 


\section{I}

\section{Introducción}

Este trabajo analiza las diferencias que fueron surgiendo a lo largo del decenio de 1990 en la inserción laboral de los migrantes recientes internos y de países limítrofes llegados al Gran Buenos Aires. ${ }^{1}$ En esa década la tasa de cambio baja y fija atrajo migraciones desde Chile, Paraguay, Uruguay, Bolivia y últimamente Perú, incluso durante los años de recesión, lo que marcó una diferencia con las corrientes migratorias internas.

Desde mediados de la década de 1970 y durante la década siguiente, la de la crisis de la deuda, el estancamiento del producto y de la demanda laboral habían inducido una reducción del ritmo de crecimiento de la fuerza de trabajo, del empleo y los ingresos. El contexto recesivo afectó el ritmo de las migraciones internas e internacionales al área metropolitana, que entre 1975 y 1980 cayó por debajo de sus niveles históricos debido a los movimientos de retorno de migrantes a las provincias y a sus países de origen. ${ }^{2}$

Los migrantes internacionales que provenían de países limítrofes y llegaban al Gran Buenos Aires habían compartido históricamente con los migrantes originarios de provincias del interior un conjunto de características. Con bajos niveles educativos y escasa calificación, se incorporaron al mercado de trabajo predominantemente en el sector informal, con peores condiciones laborales y más bajas remuneraciones que las que obtenían los nativos o los residentes más antiguos. Fueron en consecuencia relativamente más vulnerables que la población nativa a las oscilaciones cíclicas de la economía y al desempleo. ${ }^{3}$

\footnotetext{
Los autores agradecen los valiosos comentarios de un juez anónimo. ${ }^{1}$ En este trabajo se denomina "migrantes limítrofes" a la población extranjera originaria de Chile, Paraguay, Uruguay, Bolivia y Brasil, grupo poblacional al que en el decenio de 1990 se agrega la población migrante proveniente del Perú. Y se llama "migrantes internos" a aquéllos originarios de las provincias argentinas del interior. Las provincias expulsoras de población han sido predominantemente Santiago del Estero, Corrientes, Chaco, Entre Ríos, Tucumán, Salta y Jujuy. En el cuadro A.1 del apéndice se muestra la proporción de migrantes internos y limítrofes por provincia o país de origen.

2 La tasa de migración descendió de 2,3 por mil en el quinquenio 1970-1975 a -1,6 por mil entre 1975-1980 (CELADE , 1998), bajando también la proporción de migrantes interprovinciales (del 8\% al 6\%) y limítrofes (del $0.9 \%$ al $0.5 \%$ ) en la población total (INDEC, 1980). 3 Entre 1978 y 1982, por ejemplo, la desocupación en el área metropolitana de Buenos Aires -o Gran Buenos Aires- afectaba más a los migrantes que a los nativos (Cortés, 1985).
}

En la década de 1990 el comportamiento de las migraciones internas y limítrofes hacia el Gran Buenos Aires adquirió rasgos diferentes a los que habían prevalecido en la etapa anterior. En el corto período 1991-1993 coincidieron el crecimiento del producto, de la oferta de fuerza de trabajo y del empleo, y en esos años la recuperación de la economía y el aumento de la demanda laboral se convirtieron en un factor de atracción para migrantes internos, mientras que la sobrevaluación y estabilidad de la moneda local atrajeron además migrantes limítrofes. Sin embargo, a partir de la crisis de 1995 y durante el período de expansión de 1996-1999, cayó la demanda de trabajo en los sectores de inserción más tradicionales de estos migrantes, afectando el nivel de las migraciones internas. En cambio las migraciones desde países limítrofes tuvieron un comportamiento diferente; el tipo de cambio perduró hasta fines del 2001 y alentó la migración desde otros países de la región.

Junto con la disminución del flujo migratorio interno y la permanencia del limítrofe, comenzaron a esbozarse algunas diferencias en la composición y la inserción laboral de los migrantes recientes de uno y otro grupo. ${ }^{4}$ En primer lugar, si en los decenios de 1970 y 1980 ambos grupos tenían niveles educativos similares, en la década de 1990, en cambio, los migrantes limítrofes -particularmente las mujeres- llegaban con niveles educativos más altos que los migrantes internos. Segundo, comenzaron a bifurcarse las trayectorias laborales de los dos grupos. La severa crisis de 1995 contrajo la demanda de fuerza de trabajo en la construcción, el servicio doméstico y la manufactura, sectores que se convirtieron en expulsores netos de mano de obra. ${ }^{5}$ Esto dio lugar al aumento de la desocupación abierta de ambos grupos de migrantes

\footnotetext{
$\overline{{ }^{4} \text { El análisis del comportamiento de los migrantes limítrofes y }}$ recientes se circunscribe a los llegados al área en los últimos diez años, según cada medición de la Encuesta Permanente de Hogares. En el apéndice se describe la fuente de información.

${ }^{5} \mathrm{La}$ tasa de desempleo en la construcción en el total del país pasó del 14\% en 1993 al 31\% en 1995; en fechas posteriores no descendió del 23\% (Ministerio de Trabajo, www.observatorio.net). En el Gran Buenos Aires la tasa de desempleo en el servicio doméstico osciló desde 1995 alrededor del 17\%, según datos de la Encuesta Permanente de Hogares (ЕРH) que efectúa el Instituto Nacional de Estadística y Censos (INDEC).
} 
recientes, pero entre los internos aumentó además la proporción de inactivos; se extendió el "no trabajo", lo que habría alentado la desaceleración de los flujos migratorios y -esto dicho a modo de especulación, ya que no existen datos que lo comprueben o invalidenel abandono del área metropolitana.

Luego del breve período de expansión económica que finalizó en 1994, y a partir de la recesión de 1995, la baja en la proporción de migrantes internos en el área considerada indicaría que el desempleo abierto funcionó como un factor disuasivo de la migración interna hacia ella. En cambio, la sobrevaluación de la moneda local continuó atrayendo flujos migratorios desde países limítrofes (incluido Perú). La caída del empleo en las ramas tradicionalmente empleadoras de mano de obra migrante redundó en la merma de la proporción de migrantes internos, mientras aumentaba la presencia relativa de los migrantes limítrofes, quienes finalmente duraban más en el empleo. Esta situación de alto desempleo y abundancia relativa de oferta de fuerza de trabajo migrante limítrofe se prestó para la extensión de condiciones precarias de trabajo en este segmento; los trabajadores migrantes limítrofes recientes conformaron un segmento inserto en condiciones laborales de baja calidad: desprotección, alta intensidad horaria y bajos salarios. Por su parte, los migrantes internos sin ocupación o con empleos ocasionales y con pocas posibilidades de mejorar su situación en un futuro cercano, pasaron a engrosar el núcleo más duro de desempleados, proclives a caer en la pobreza estructural.

\section{II}

\section{Migraciones y mercado de trabajo en Argentina}

\section{El debate en los decenios de 1980 y 1990}

Los estudios elaborados desde fines de la década de 1970 hasta la de 1990 coinciden en caracterizar a los migrantes internos y limítrofes como uno de los segmentos más vulnerables a las oscilaciones económicas. Pero no coinciden en su interpretación de las características del mercado de trabajo o del papel de los migrantes en él. Una línea de investigación sostuvo que hasta el decenio de 1980 Argentina enfrentaba escasez de fuerza de trabajo no calificado, $\mathrm{y}$, en consecuencia, que la dinámica de crecimiento económico era suficiente como para que los migrantes fueran absorbidos e integrados al mercado de trabajo urbano (Mármora, 1977). En cambio, otras interpretaciones más lewisianas (Marshall, 1977) argumentaron que el mercado de trabajo local se caracterizaba por la falta de dinamismo de la demanda de trabajo no calificado, y por la presencia de un segmento de trabajadores excedentes. Según este argumento la demanda de migraciones sufría de la misma falta de dinamismo; los migrantes no eran demandados por la economía receptora, ya que provenían de procesos de expulsión de las economías de origen, y por lo tanto ingresaban a ocupaciones en el margen del mercado de trabajo formal. Según esta visión, el ritmo de crecimiento de la manufactura y del proceso de urbanización tuvieron un papel central en las variaciones del volumen migratorio así como en las características de la inserción de los migrantes en el área metropolitana. Ciertos autores (Marshall, 1977; Marshall y Orlanski, 1983) describieron desde esta perspectiva cómo en el decenio de 1960, a raíz de la modernización tecnológica, el segmento concentrado de la industria se había desprendido de fuerza de trabajo no calificada, y los migrantes debieron insertarse en la construcción y en la pequeña industria.

A fines de la década de 1980 los estudios sobre la pobreza incluyeron la dimensión migratoria; una investigación sobre las relaciones entre migración y pobreza encontró indicaciones de que en 1988, en el Gran Buenos Aires, la incidencia de la pobreza en los migrantes recientes era mayor en los limítrofes que en los internos (Maguid, 1990, p.25). Además, en ese estudio se argumenta que el nivel educativo de los 
migrantes recientes limítrofes era inferior al de los migrantes internos, información que difiere de la que se maneja en este trabajo. ${ }^{6}$

El debate en torno a la sanción de reglamentaciones y leyes poblacionales durante el decenio de 1990 -tanto la amnistía y los acuerdos bilaterales como los decretos de expulsión de ilegales- revivieron el interés por la relación migraciones-mercado de trabajo. El debate público giró alrededor del papel de las migraciones limítrofes en el aumento de la tasa de desempleo, mientras se discutía en qué medida los migrantes limítrofes competían por puestos de trabajo: en otras palabras, en qué medida se les podía "responsabilizar" del alto desempleo.

Entre los temas debatidos destacaron dos: el ritmo de las migraciones desde países limítrofes en la década de 1990 y las características de su inserción en el mercado de trabajo. Con respecto al primero, Lattes (1997) cuestiona las proyecciones demográficas que preveían saldos migratorios nulos hasta 2015, pues según sus estimaciones el volumen de migraciones limítrofes no se interrumpió. ${ }^{7}$ Además, argumenta que la población activa y las tasas de participación en la actividad económica aumentaron en la década de 1990 por el impacto de las migraciones, el crecimiento vegetativo y otros factores como la mayor propensión a participar de las mujeres. En cambio, Maguid (2001), minimizando el papel que tuvo la tasa de cambio baja y fija como incentivo para los migrantes limítrofes, planteó que en la primera mitad del decenio de 1990 la retracción de la demanda laboral por sí sola redujo la migración limítrofe.

Respecto a la inserción laboral de los migrantes, una proporción no desdeñable de autores locales sostuvo la hipótesis de que los segmentos limítrofe e interno de la migración reciente no competían por puestos de trabajo, sino que entre ellos más bien existía un cierto grado de "complementación" o de "ausencia de competencia" (Mármora, 1994). Fue el caso, por ejemplo, de autores como Maguid (1995) y Benencia y Gazotti (1995) que han planteado que la contribución de la migración limítrofe al desempleo abierto en el área metropolitana ha sido ínfima. Montoya y Perticará (1995) llegaron a la misma conclusión, si bien se

\footnotetext{
${ }^{6}$ El trabajo de Maguid (1990) se basó en datos de 1990 del proyecto Investigación sobre Pobreza en Argentina (IPA), si se utiliza como fuente la $\mathrm{EPH}$, en 1980 no había diferencias entre el nivel educativo de migrantes recientes limítrofes e internos.

${ }^{7}$ En Lattes (1997), los flujos de migrantes se estimaron utilizando datos para 1991-1996 de la EPH, compatibilizados con los del Censo Nacional de Población y Vivienda de 1991.
}

preguntan en qué medida puede extenderse a todos los migrantes internos, ya que, desde su punto de vista, los migrantes internos originarios de provincias de menor desarrollo relativo podrían haber incidido en el nivel de desempleo.

Marshall (2000) argumentó en cambio que habría indicios para sostener que las migraciones limítrofes -en el margen- competían con otros migrantes recientes por los mismos puestos de trabajo. Revisando la posición que sostuvieron en 1995, en trabajos posteriores, Benencia (2000) y Maguid (2001) aceptan la posibilidad de que haya existido un cierto nivel de competencia entre migrantes limítrofes y nativos recientes en el área metropolitana. Maguid, en este último trabajo, plantea que el impacto de las migraciones provenientes de países limítrofes sobre el mercado de trabajo local dependió del nivel de actividad económica. Abonando la posición que afirmaba que había escasez de fuerza de trabajo no calificada en el mercado de trabajo urbano argentino, argumenta que en períodos en que la demanda de mano de obra fue sostenida, como durante la industrialización sustitutiva, los nativos rechazaban los empleos de mala calidad. En su revisión aduce que en el decenio de 1990 la caída del producto manufacturero y otros cambios redujeron el nivel de la demanda laboral, lo que habría llevado a los nativos a estar "dispuestos a desempeñar ocupaciones que antes despreciaban" (Maguid, 2001, p.67). Acepta por consiguiente que el nuevo contexto recesivo habría incentivado la competencia migrante-nativo en la construcción y el servicio doméstico y además habría redundado en una reversión de los flujos migratorios limítrofes. Sin embargo reconoce que "no se cuenta con información confiable...para conocer si ha disminuido la inmigración o si hay un recambio entre nuevos y antiguos migrantes que retornan a sus países de origen" (Maguid, 2001, p.65). Desde la perspectiva que se sostiene en el presente artículo, este análisis otorga excesivo peso a la decisión voluntaria de la población nativa y migrante interna de no competir con los migrantes limítrofes, y resta importancia al papel de la demanda laboral en la distribución de los puestos de trabajo.

En este artículo se postula que en la década de 1990 continuó el flujo de migraciones limítrofes, ${ }^{8}$ y que durante las fases expansivas del ciclo económico

\footnotetext{
${ }^{8}$ Entre 1993 y 2001 la población migrante reciente (10 años de residencia) en el área metropolitana de Buenos Aires bajó de 141.093 a $105.017(25 \%)$ y los migrantes limítrofes subieron de 230.504 a 265.852 (15\%), según la EPH. La población ocupada de migrantes internos cayó de 1.061 .388 a 933.027 (12\%).
} 
el empleo de los migrantes limítrofes creció más rápidamente que el de los migrantes internos, justamente en las mismas ramas de actividad donde se concentraban estos últimos. En cambio si bien durante las recesiones la construcción y el servicio doméstico expulsaron a ambos tipos de migrantes, en la recuperación solamente creció el empleo de los limítrofes en esos mismos sectores, no sucediendo lo mismo con los migrantes internos". 9

Las diferencias en los niveles de calificación a favor de los limítrofes, así como su aceptación de bajos salarios y alta intensidad horaria, crearon condiciones que hicieron más atractiva la contratación de este segmento. A partir de 1995 se produjo una caída de las migraciones internas al área; es probable que el alto desempleo prevaleciente en ella haya causado migración hacia otros centros urbanos, desocupación abierta, desaliento, inserción intermitente, es decir, distintas variedades de un proceso creciente de desafiliación laboral.

Este panorama sugiere que se habría producido la sustitución de trabajadores de la construcción y del servicio doméstico que eran migrantes internos recientes por migrantes limítrofes recientes. Los procesos de exclusión del mercado laboral se sumaron a otras privaciones y afectaron más fuertemente a los migrantes internos recientes. Este grupo habría estado nutriendo, a lo largo de los últimos diez años, a un sector invisible en las estadísticas, oculto tras la inactividad, que podríamos clasificar como relativamente excluido. $\mathrm{Si}$ bien en la actualidad la información disponible no aporta evidencia suficiente para confirmar esta tendencia, el tema amerita futuras investigaciones.

\section{El marco regulatorio}

El área metropolitana de Buenos Aires fue un centro de atracción de las migraciones internas e internacionales desde la década de 1930 hasta mediados de la década de 1970. La desaceleración de las migraciones elevó la proporción de nativos y disminuyó el peso de los migrantes en la población del área. ${ }^{10}$ Sin embargo la

\footnotetext{
${ }^{9}$ Después de una caída de la proporción de migrantes recientes limítrofes e internos ocupados en la construcción entre 1994 y 1995, en 1996 continuó cayendo la proporción de migrantes internos, mientras aumentaba la de limítrofes. Estos últimos constituían el $40 \%$ en 1995 , el $53 \%$ en 1996 , el $57 \%$ en 1997 y el $58 \%$ en 1998 (elaboración propia basada en datos de la EPH).

${ }^{10}$ En el área metropolitana, entre los censos de 1980 y 1991, la proporción de migrantes internacionales no limítrofes en la población bajó del 4,4\% al 2,5\% y la de migrantes internos descendió del $22,6 \%$ al $19,5 \%$. En cambio, la proporción de no migrantes creció del 70,6\% al 75,5\% (INDEC, 1991).
}

migración limítrofe continuó concentrándose allí ${ }^{11} \mathrm{y}$ este patrón de distribución geográfica persistiría en el decenio de 1990: habitaba el Gran Buenos Aires el 70\% de los migrantes limítrofes con residencia en las áreas urbanas, el 75\% de los migrantes limítrofes ocupados llegados en los últimos diez años, y el 78\% de los llegados en los últimos cinco años. ${ }^{12}$

Durante los años del régimen militar (1976-1983) la legislación sobre migraciones fue predominantemente restrictiva. En 1981 se aprobó la Ley General de Migraciones y de Fomento de la Inmigración ${ }^{13}$ que estuvo dirigida a propugnar exclusivamente "la inmigración de extranjeros cuyas características culturales permitan su adecuada integración", y a desalentar la proveniente de países limítrofes. Un punto importante fue la imposición de restricciones al trabajo de los residentes transitorios y temporarios: tanto ellos como los empleadores que optaran por contratar no nativos debían cumplir con una serie de requisitos. A partir de este hito, e incluso una vez iniciada la etapa democrática, la legislación no tuvo una orientación lineal; si bien ciertos decretos restringían los flujos migratorios, también se sancionaron amnistías, como por ejemplo la de 1984. En 1985 (decreto 828/85), se establecieron nuevamente restricciones a la migración -que fueron intensificadas en 1987 con la reglamentación del permiso de ingreso, que dificultaba la tramitación de una residencia legalizada-y se aplicaron políticas de control más estricto de la migración. En el decenio de 1990 se suscribieron convenios bilaterales más permisivos respecto del ingreso de nacionales de países limítrofes. Sin embargo el marco regulatorio no desempeñó un papel disuasivo continuo respecto de la decisión de migrar o del empleo de migrantes, ya que no siempre se pusieron en práctica controles efectivos del cumplimiento de la legislación restrictiva. La falta de controles hizo posible la utilización de fuerza de trabajo migrante limítrofe, que de todas maneras se hacía al margen de la legalidad.

Esta situación de ilegalidad contribuyó a que los trabajadores originarios de países limítrofes aceptaran condiciones de trabajo precarias (desprotección jubilatoria, mayor intensidad de trabajo, falta de acceso a la representación gremial, entre otras). Y si bien en términos estrictamente jurídicos no había obstáculos

\footnotetext{
${ }^{11}$ En la Ciudad de Buenos Aires, entre 1980 y 1991, la proporción de migrantes limítrofes aumentó del 2,9\% al 3,9\% y se mantuvo constante en los 19 partidos del conurbano bonaerense (INDEC, 1991). ${ }^{12}$ Estimaciones propias basadas en datos de la EPH.

13 Texto de la Ley General de Migraciones y de Fomento de la Inmigración, No 22439/1981. Véase CELS (2000) y Novick (2001).
} 
para entablar juicios laborales, la nacionalidad puede haber constituido un desincentivo para la iniciación de demandas por parte de los trabajadores..$^{14}$ Las dificultades de acceso a la justicia, sumadas a un creciente desempleo, creaban condiciones propicias para que se extendiera el uso de la fuerza de trabajo limítrofe con estándares cada vez más deteriorados. El incremento de los costos de producción no laborales (energía, comunicaciones, transporte) estimuló a las empresas a emplear estrategias tendientes a abaratar el componente laboral de los costos, como la contratación de trabajadores migrantes. Y la contratación de migrantes limítrofes fue más conveniente que la de migrantes internos ya que, por una parte, sus calificaciones no eran inferiores a las de estos últimos y por la otra, conformaban una fuerza de trabajo altamente disciplinada.

\section{III}

\section{Migrantes internos y migrantes limítrofes en el decenio de 1990}

\section{Actividad, empleo y desempleo}

Entre 1993 y 2000 las variaciones de los flujos migratorios limítrofes como proporción de la población total y de la población activa estuvieron asociadas a la evolución del PIB total, y, en particular, a la de los sectores donde se concentraban los migrantes limítrofes recientes. En cambio, en el caso de los migrantes internos la asociación migración/producto fue negativa (cuadro 1). La demanda de mano de obra desde los sectores económicos típicos de inserción migrante, dirigida más claramente hacia los migrantes limítrofes, fue uno de los factores que provocaron cambios en la composición de la población total y la población activa. El peso de los grupos migratorios de distinto origen en la población varió en esos años: la proporción de migrantes internos decayó levemente pero la de migrantes limítrofes tuvo una tendencia al alza (cuadro 2). La población económicamente activa sufrió cambios en la misma dirección, pues cayó la proporción de migrantes internos y aumentó levemente la de migrantes limítrofes (cuadro 3).

La dirección de estos cambios se refleja además en los distintos ritmos de crecimiento de la población

CUADRO 1

Argentina: Coeficientes de correlación del producto interno bruto y la migración

\begin{tabular}{|c|c|c|c|c|c|}
\hline $\begin{array}{l}\text { 1993-2000 } \\
\text { Grupos de población según origen migratorio }\end{array}$ & PIB & $\begin{array}{c}\text { PIB } \\
\text { manufactura }\end{array}$ & $\begin{array}{l}\text { PIB } \\
\text { construcción }^{\mathrm{a}}\end{array}$ & $\begin{array}{l}\text { PIB } \\
\text { servicios }^{b}\end{array}$ & $\begin{array}{c}\text { PIB } \\
\text { comercio }^{c}\end{array}$ \\
\hline Migrantes internos / población total & $-0,13$ & $-0,10$ & $-0,36$ & $-0,16$ & $-0,05$ \\
\hline Migrantes internos recientes / población total & $-0,53$ & $-0,50$ & $-0,63$ & $-0,55$ & $-0,42$ \\
\hline Migrantes limítrofes / población total & 0,90 & 0,71 & 0,69 & 0,93 & 0,67 \\
\hline Migrantes limítrofes recientes / población total & 0,49 & 0,26 & 0,68 & 0,60 & 0,19 \\
\hline Migrantes internos / población económicamente activa & 0,06 & 0,13 & $-0,16$ & $-0,06$ & 0,19 \\
\hline Migrantes internos recientes / población económicamente activa & $-0,60$ & $-0,54$ & $-0,63$ & $-0,62$ & $-0,45$ \\
\hline Migrantes limítrofes / población económicamente activa & 0,82 & 0,61 & 0,59 & 0,89 & 0,55 \\
\hline Migrantes limítrofes recientes / población económicamente activa & 0,34 & 0,05 & 0,19 & 0,47 & $-0,03$ \\
\hline
\end{tabular}

Fuente: Elaboración propia sobre datos (valores absolutos) de producto interno bruto para el total del país (Ministerio de Economía, año base 1993, a precios corrientes), y datos (valores absolutos) de registros de octubre de la Encuesta Permanente de Hogares, Gran Buenos Aires.

a En el caso del sector de la construcción los coeficientes de correlación se han calculado para el período $1993-1999$ para evitar el sesgo que ocasiona la pronunciada caída de la actividad del sector en 2000. Mientras que la crisis del tequila ocasionó una caída del $6 \%$ en el producto de la construcción (1994-1995), la retracción entre 1999 y 2000 fue de $-13 \%$.

b Incluye servicios sociales, comunitarios y personales; excluye educación, salud y administración pública.

c Comercio mayorista, minorista y reparaciones.

\footnotetext{
${ }^{14}$ Entrevista con el Dr. Pedro I. Galín, Consultor en temas laborales, Buenos Aires, 4 de octubre de 2002
} 
económicamente activa, de la población ocupada y de los desocupados. El crecimiento de los migrantes internos económicamente activos se estancó, mientras aumentaban los desempleados y caían los ocupados de este segmento. En cambio, crecieron los activos, los ocupados y los desocupados limítrofes. El factor que diferenció el comportamiento de los dos tipos de migrantes fue que el empleo aumentó solamente entre los limítrofes (cuadro 4 y gráfico A.1 del apéndice).

La descomposición de las variaciones en el volumen de las subpoblaciones de ocupados y desocupados (cuadro 5) muestra que entre 1993 y 1995 los migrantes limítrofes tuvieron un papel más importante que los migrantes internos e incluso que los nativos en la variación del nivel de empleo. Analizando los otros períodos se observa que, si bien la contribución más relevante fue la de los no migrantes, el aporte de los migrantes limítrofes al empleo y la actividad fue mayor que el de los migrantes internos. Estos último, en todos los períodos, contribuyeron más que el resto a la desocupación urbana. El cuadro 4 sugiere que durante los períodos recesivos los migrantes recientes internos y limítrofes perdían el empleo más frecuentemente que los nativos, si bien la pérdida era

CUADRO 2

Gran Buenos Aires: Composición de la población según su condición migratoria (Porcentajes)

\begin{tabular}{|c|c|c|c|c|c|}
\hline Años & Población total & $\begin{array}{l}\text { Población total } \\
\text { no migrante }\end{array}$ & $\begin{array}{l}\text { Población total } \\
\text { migrante interna }\end{array}$ & $\begin{array}{l}\text { Población total } \\
\text { migrante limítrofe }\end{array}$ & $\begin{array}{l}\text { Población total migrante } \\
\text { Resto internacional }\end{array}$ \\
\hline 1993 & 100 & 73,4 & 18,1 & 3,8 & 4,7 \\
\hline 1994 & 100 & 72,9 & 19,1 & 3,6 & 4,4 \\
\hline 1995 & 100 & 72,8 & 18,8 & 4,0 & 4,4 \\
\hline 1996 & 100 & 72,5 & 19,0 & 4,2 & 4,2 \\
\hline 1997 & 100 & 73,4 & 18,2 & 4,5 & 3,9 \\
\hline 1998 & 100 & 74,7 & 17,5 & 4,6 & 3,2 \\
\hline 1999 & 100 & 75,3 & 16,9 & 4,7 & 3,1 \\
\hline 2000 & 100 & 76,0 & 16,8 & 4,3 & 2,9 \\
\hline 2001 & 100 & 75,8 & 17,0 & 4,6 & 2,6 \\
\hline
\end{tabular}

Fuente: Encuesta Permanente de Hogares (ЕPH).

CUADRO 3

Gran Buenos Aires: Composición de la población económicamente activa según su condición migratoria, años 1993 a 2001

(Porcentajes)

\begin{tabular}{|c|c|c|c|c|c|}
\hline Años & $\begin{array}{l}\text { Población económicamente } \\
\text { activa total }\end{array}$ & $\begin{array}{l}\text { PEA no } \\
\text { migrante }\end{array}$ & $\begin{array}{l}\text { PEA migrante } \\
\text { interna }\end{array}$ & $\begin{array}{l}\text { PEA migrante } \\
\text { limítrofe }\end{array}$ & $\begin{array}{c}\text { PEA migrante } \\
\text { Resto internacional }\end{array}$ \\
\hline 1993 & 100 & 67,1 & 24,0 & 5,4 & 3,5 \\
\hline 1994 & 100 & 66,8 & 25,0 & 5,0 & 3,1 \\
\hline 1995 & 100 & 65,8 & 24,9 & 5,8 & 3,5 \\
\hline 1996 & 100 & 66,6 & 24,5 & 5,8 & 3,1 \\
\hline 1997 & 100 & 67,4 & 23,4 & 6,2 & 3,0 \\
\hline 1998 & 100 & 68,5 & 22,8 & 6,2 & 2,5 \\
\hline 1999 & 100 & 69,5 & 21,6 & 6,5 & 2,4 \\
\hline 2000 & 100 & 70,8 & 21,0 & 6,1 & 2,2 \\
\hline 2001 & 100 & 71,1 & 21,0 & 6,2 & 1,6 \\
\hline
\end{tabular}

Fuente: Encuesta Permanente de Hogares (EPH), registros de octubre, Gran Buenos Aires.

CUADRO 4

Gran Buenos Aires: Tasas de variación media anual de la población total, activa, ocupada y desocupada, 1993-2001

(Porcentajes)

\begin{tabular}{lccrr}
\hline Población & $\begin{array}{c}\text { No } \\
\text { migrantes }\end{array}$ & $\begin{array}{c}\text { Migrantes } \\
\text { internos }\end{array}$ & $\begin{array}{c}\text { Migrantes } \\
\text { limítrofes }\end{array}$ & $\begin{array}{c}\text { Resto de migrantes } \\
\text { internacionales }\end{array}$ \\
\hline Población total & 1,93 & 0,75 & 4,00 & $-5,76$ \\
Población económicamente activa & 2,52 & 0,10 & 3,47 & $-7,57$ \\
Población ocupada & 1,23 & $-1,60$ & 1,80 & $-8,69$ \\
Población desocupada & 10,97 & 10,67 & 1,79 & 0,32 \\
\hline
\end{tabular}

Fuente: Encuesta Permanente de Hogares (EPH), registros de octubre, Gran Buenos Aires. 
Gran Buenos Aires: Descomposición de los incrementos en las subpoblaciones según su condición migratoria, en períodos seleccionados

(Porcentajes)

\begin{tabular}{|c|c|c|c|c|c|}
\hline Períodos & $\begin{array}{c}\text { No } \\
\text { migrantes }\end{array}$ & $\begin{array}{l}\text { Migrantes } \\
\text { internos }\end{array}$ & $\begin{array}{l}\text { Migrantes } \\
\text { limítrofes }\end{array}$ & $\begin{array}{l}\text { Resto de migrantes } \\
\text { internacionales }\end{array}$ & Total $^{\mathrm{a}}$ \\
\hline \multicolumn{6}{|c|}{ Población total } \\
\hline $1995-1993$ & 45 & 44 & 11 & & 100 \\
\hline $1997-1993$ & 63 & 18 & 19 & & 100 \\
\hline $2001-1993$ & 83 & 8 & 10 & & 100 \\
\hline \multicolumn{6}{|c|}{ Población económicamente activa } \\
\hline $1995-1993$ & 37 & 45 & 14 & 3 & 100 \\
\hline $1997-1993$ & 69 & 15 & 15 & & 100 \\
\hline $2001-1993$ & 89 & 1 & 10 & & 100 \\
\hline \multicolumn{6}{|c|}{ Población ocupada } \\
\hline $1995-1993$ & & & 100 & & 100 \\
\hline $1997-1993$ & 68 & & 32 & & 100 \\
\hline $2001-1993$ & 89 & & 11 & & 100 \\
\hline \multicolumn{6}{|c|}{ Población desocupada } \\
\hline 1995-1993 & 64 & 26 & 7 & 3 & 100 \\
\hline $1997-1993$ & 65 & 25 & 5 & 4 & 100 \\
\hline $2001-1993$ & 69 & 23 & 8 & 1 & 100 \\
\hline
\end{tabular}

Fuente: Encuesta Permanente de Hogares (EPH), registros de octubre, Gran Buenos Aires.

a Los totales excluyen los casos en que no se especifica condición migratoria.

mayor entre los migrantes recientes internos. Los migrantes recientes internos no afectaron el nivel de empleo o de actividad; en cambio, contribuyen a explicar las variaciones de la desocupación en distintos períodos.

En la década de 1990 se expandió la tasa de actividad y de desempleo de la población total del Gran Buenos Aires. Para estimar en qué medida las variaciones en el volumen de la oferta de trabajo afectaron las tasas de desempleo de las distintas subpoblaciones, planteamos el ejercicio siguiente. Se calculó el valor que habría alcanzado la tasa de desempleo entre 1993-2000 con una tasa de actividad constante y se comparó con la tasa de desempleo observada (tasa de desempleo real); el coeficiente resultante se tomó como variable sustitutiva del efecto neto de la demanda de trabajo, que indica la porción del desempleo provocada por la destrucción de puestos de trabajo. Como se ve en el cuadro 6, el efecto neto de la demanda de trabajo difiere entre grupos de población según el sexo y el origen migratorio.

Para el conjunto de la fuerza de trabajo las variaciones de la tasa de participación tuvieron algo más de peso que la destrucción de empleo en el aumento de la desocupación (3,1 puntos porcentuales y 2,2 puntos porcentuales, respectivamente). En cambio, los grupos con distinto origen migratorio tuvieron un comportamiento particular. i) No migrantes. La tendencia general se manifestó con mayor fuerza en las mujeres que en los varones. Entre las mujeres la expansión de la tasa de participación impulsó la de la desocupación. Entre los varones ambos factores contribuyeron por igual al aumento de la desocupación.

ii) Migrantes internos. Los varones se caracterizaron por la caída de la tasa de actividad, factor que contribuyó a amortiguar el aumento que hubiera alcanzado la tasa de desocupación por efecto de la destrucción de puestos de trabajo. En efecto, de no haberse producido esta retracción de la oferta de trabajo en el caso de los varones, la tasa de desocupación de este grupo hubiera trepado más de 12 puntos porcentuales. En cambio el aumento de la desocupación de las mujeres migrantes internas provino en partes iguales de la destrucción de puestos de trabajo y del aumento de la oferta de trabajo.

iii) Migrantes limítrofes. Las mujeres migrantes limítrofes aumentaron su tasa de participación, pero el incremento en la tasa de empleo fue aún mayor, razón por la cual entre ellas cayó el desempleo. En el caso de los varones migrantes limítrofes, la destrucción de puestos de trabajo fue el factor más determinante del aumento del desempleo. 
CUADRO 6

Gran Buenos Aires: Cambios en la desocupación, según condición migratoria (Porcentajes)

\begin{tabular}{|c|c|c|c|c|c|}
\hline $\begin{array}{l}\text { Población según } \\
\text { condición migratoria }\end{array}$ & $\begin{array}{c}\text { Tasa de } \\
\text { desocupación } \\
1993\end{array}$ & $\begin{array}{c}\text { Tasa de } \\
\text { desocupación } \\
2000\end{array}$ & $\begin{array}{l}\text { Efecto } \\
\text { empleo }\end{array}$ & $\begin{array}{c}\text { Efecto } \\
\text { actividad }\end{array}$ & $\begin{array}{c}\text { Diferencia entre } \\
\text { tasas de desempleo, } \\
1993 \text { y } 2000\end{array}$ \\
\hline Población activa total & 9,6 & 14,9 & 2,2 & 3,1 & 5,3 \\
\hline $\begin{array}{c}\text { No migrantes } \\
\text { Varones } \\
\text { Mujeres }\end{array}$ & $\begin{array}{r}10,2 \\
8,0 \\
13,7\end{array}$ & $\begin{array}{l}14,8 \\
12,6 \\
18,0\end{array}$ & $\begin{array}{r}-0,3 \\
2,5 \\
-5,4\end{array}$ & $\begin{array}{l}4,9 \\
2,0 \\
9,7\end{array}$ & $\begin{array}{l}4,6 \\
4,6 \\
4,3\end{array}$ \\
\hline $\begin{array}{l}\text { Migrantes internos } \\
\text { Varones } \\
\text { Mujeres }\end{array}$ & $\begin{array}{l}8,3 \\
7,4 \\
9,6\end{array}$ & $\begin{array}{l}16,0 \\
14,7 \\
17,9\end{array}$ & $\begin{array}{r}9,5 \\
12,5 \\
4,2\end{array}$ & $\begin{array}{r}-1,7 \\
-5,3 \\
4,1\end{array}$ & $\begin{array}{l}7,8 \\
7,3 \\
8,4\end{array}$ \\
\hline $\begin{array}{l}\text { Migrantes limítrofes } \\
\text { Varones } \\
\text { Mujeres }\end{array}$ & $\begin{array}{l}12,1 \\
11,7 \\
12,6\end{array}$ & $\begin{array}{l}14,4 \\
17,6 \\
10,3\end{array}$ & $\begin{array}{r}0,5 \\
5,8 \\
-4,7\end{array}$ & $\begin{array}{l}1,9 \\
0,1 \\
2,3\end{array}$ & $\begin{array}{r}2,3 \\
5,9 \\
-2,4\end{array}$ \\
\hline
\end{tabular}

Fuente: Encuesta Permanente de Hogares (EPH), registros de octubre, Gran Buenos Aires.

En el cuadro 7 se estima el efecto de la migración limítrofe sobre las tasas de actividad y de desocupación generales. Ambas tasas se recalcularon bajo el supuesto de que no hubiera aumentado la migración limítrofe desde 1993, e incluso llegando al extremo de suponer que en los últimos diez años no hubiera habido ingreso de migrantes. Las diferencias son leves. En efecto, si bien el signo es el esperado (disminución en ambas tasas), dada la magnitud relativamente menor de los migrantes limítrofes en relación al resto de los grupos,

Gran Buenos Aires: Recálculo de tasas de actividad y desocupación (Porcentajes)

A. Tasa de actividad

\begin{tabular}{|c|c|c|c|c|c|}
\hline & $\begin{array}{c}\text { No } \\
\text { migrantes }\end{array}$ & $\begin{array}{c}\text { Migrantes } \\
\text { internos }\end{array}$ & $\begin{array}{l}\text { Migrantes } \\
\text { limitrofes }\end{array}$ & Total & $\begin{array}{l}\text { Dif. \% respecto de } \\
\text { la tasa observada }\end{array}$ \\
\hline 1993 & 39,5 & 57,3 & 62,2 & 43,3 & \\
\hline 1996 & 41,1 & 57,7 & 61,2 & 44,9 & \\
\hline 2001 & 41,4 & 54,4 & 59,7 & 44,1 & \\
\hline $1996^{\mathrm{a}}$ & & & & 44,8 & $-0,06$ \\
\hline $1996^{\mathrm{b}}$ & & & & 44,6 & $-0,22$ \\
\hline $2001^{\mathrm{a}}$ & & & & 44,0 & $-0,11$ \\
\hline $2001^{b}$ & & & & 44,0 & $-0,11$ \\
\hline
\end{tabular}

B. Tasa de desempleo

\begin{tabular}{|c|c|c|c|c|c|}
\hline & $\begin{array}{c}\text { No } \\
\text { migrantes }\end{array}$ & $\begin{array}{c}\text { Migrantes } \\
\text { internos }\end{array}$ & $\begin{array}{l}\text { Migrantes } \\
\text { limítrofes }\end{array}$ & Total & $\begin{array}{l}\text { Dif. \% respecto de } \\
\text { la tasa observada }\end{array}$ \\
\hline $\begin{array}{l}1993 \\
1996 \\
2001 \\
1996^{\mathrm{c}} \\
1996^{\mathrm{d}} \\
2001^{\mathrm{c}} \\
2001^{\mathrm{d}}\end{array}$ & $\begin{array}{l}10,2 \\
19,1 \\
18,8\end{array}$ & $\begin{array}{r}8,3 \\
19,3 \\
20,0\end{array}$ & $\begin{array}{l}12,1 \\
19,3 \\
22,8\end{array}$ & $\begin{array}{r}9,6 \\
18,8 \\
19,3 \\
18,5 \\
17,6 \\
18,7 \\
17,9\end{array}$ & $\begin{array}{l}-0,4 \\
-1,2 \\
-0,6 \\
-1,4\end{array}$ \\
\hline
\end{tabular}

Fuente: Encuesta Permanente de Hogares (EPH), registros de octubre, Gran Buenos Aires.

a Nueva tasa, suponiendo ausencia de nuevos migrantes limítrofes desde 1993. La cantidad de migrantes limítrofes activos y totales sería igual a la de 1993.

b Nueva tasa, sin migrantes limítrofes recientes.

c Nueva tasa, suponiendo que la desocupación de migrantes limítrofes es igual a la de 1993.

d Nueva tasa, sin desocupados migrantes limítrofes recientes y sin ocupados migrantes limítrofes recientes, redistribuyendo los puestos de trabajo. 
la proporción en la que esas tasas caen es marginal: la tasa de actividad disminuye en menos de un punto porcentual y la tasa de desocupación abierta en poco más de ese valor (en ambos casos bajo el supuesto más restrictivo).

Se estimó también el impacto de las migraciones en las tendencias que son esperables para las tasas de actividad, empleo y desempleo según el comportamiento observado a lo largo del decenio de 1990. Mediante el análisis de regresiones lineales por mínimos cuadrados ordinarios se tomaron como variables independientes la proporción de migrantes internos y limítrofes en la oferta de trabajo y en la población ocupada y como variables dependientes las tasas mencionadas (cuadros A. 2 y A. 3 del apéndice) ${ }^{15} \mathrm{El}$ análisis de las regresiones muestra que las migraciones limítrofes afectaron casi exclusivamente a los jóvenes no calificados, pero no al resto de los grupos de edad, ni a aquellos con niveles altos de educación (por ejemplo, la tasa de empleo de los menores de 30 años con enseñanza secundaria incompleta cae frente a la presencia de migrantes limítrofes recientes en la oferta de trabajo).

En síntesis, los cuadros indican que se detuvieron las migraciones internas, no así aquellas desde países limítrofes, y esto afectó el peso de ambos grupos en la población activa. El volumen de migrantes no fue suficiente para afectar las tasas de actividad, empleo o desempleo. Además, creció la actividad económica de las mujeres no migrantes nativas, migrantes internas y migrantes limítrofes; pero sólo en las mujeres migrantes internas se concentraron las pérdidas de puestos de trabajo. Por su parte, en el caso de los varones bajó la proporción de ocupados en los tres grupos, pero la caída de mayor magnitud se dio entre los migrantes internos.

\section{Inserción ocupacional}

Para analizar la inserción ocupacional de migrantes se utilizó una mancomunación de datos, adicionando los registros de octubre de la EPH en los años 1993, 1995, 1997, 1999 y 2001; esto permitió aumentar la cantidad de casos para hacer posible el análisis, bajo el supuesto de que a lo largo del período los grupos mantienen características comunes. ${ }^{16}$

En la década de 1990 los patrones de inserción sectorial de los ocupados migrantes -tanto limítrofes

\footnotetext{
${ }^{15}$ Para contar con observaciones suficientes se utilizaron los registros de mayo y octubre de la EPH entre octubre de 1993 y mayo de 2002.

${ }^{16}$ Véase el segundo párrafo del apéndice.
}

como provinciales- llegados al área del Gran Buenos Aires no habían cambiado sustancialmente respecto de las tendencias vigentes con anterioridad. Continuaría la concentración del conjunto migrante (independientemente del año de llegada) en la construcción, el servicio doméstico, y la rama textil, si bien en esta década los limítrofes tuvieron mayor peso. Estos tres sectores ocupaban al 46,4\% de los migrantes limítrofes y el $32,3 \%$ de los migrantes internos recientes; por otra parte, si no se tiene en cuenta el año de llegada, una proporción más alta de limítrofes que de internos trabajaba en estas actividades: $57,6 \%$ y $27 \%$, respectivamente.

Durante la etapa de crecimiento económico - hasta 1995- los migrantes limitrofes continuaron siendo demandados por el crecimiento de sectores económicos urbanos típicos, lo que no sucedía con los migrantes internos; en cambio, en la etapa recesiva, cuando la construcción y la manufactura se transformaron en expulsores netos de fuerza de trabajo, ambos grupos de migrantes se vieron afectados por la caída de la demanda de fuerza de trabajo.

CUADRO 8

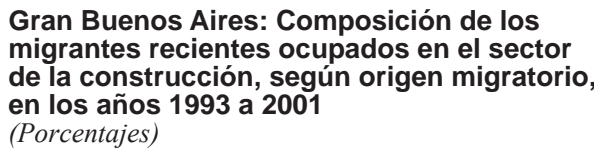

\begin{tabular}{cccc}
\hline Años & $\begin{array}{c}\text { Migrantes recientes } \\
\text { internos }\end{array}$ & $\begin{array}{c}\text { Migrantes recientes } \\
\text { limítrofes }\end{array}$ & Total \\
\hline 1993 & 58,5 & 41,5 & 100 \\
1995 & 45,7 & 54,3 & 100 \\
1997 & 33,1 & 66,9 & 100 \\
1999 & 6,9 & 93,1 & 100 \\
2001 & 19,7 & 80,3 & 100 \\
\hline
\end{tabular}

Fuente: Elaboración propia sobre datos de registros de octubre de la Encuesta Permanente de Hogares (EPH).

CUADRO 9

Gran Buenos Aires: Composición de los migrantes recientes ocupados en el servicio doméstico, según su origen migratorio, en los años 1993 a 2001

(Porcentajes)

\begin{tabular}{cccc}
\hline Años & $\begin{array}{c}\text { Migrantes recientes } \\
\text { internos }\end{array}$ & $\begin{array}{c}\text { Migrantes recientes } \\
\text { limítrofes }\end{array}$ & Total \\
\hline 1993 & 45 & 55 & 100 \\
1995 & 41,5 & 58,5 & 100 \\
1997 & 21 & 79 & 100 \\
1999 & 29,1 & 70,9 & 100 \\
2001 & 8,9 & 91,1 & 100 \\
\hline
\end{tabular}

Fuente: Elaboración propia sobre registros de octubre de la Encuesta Permanente de Hogares (EPH). 
Los migrantes limítrofes ocuparon puestos que antes ocupaban los internos, en los empleos asalariados no registrados en la construcción y en el servicio doméstico, y en menor medida en la industria del vestido y el calzado; los internos se refugiaron más frecuentemente en empleos por cuenta propia.

Entre los varones, el $36,4 \%$ de los migrantes limítrofes recientes y el $10,7 \%$ de los internos estaba ocupado en la construcción; entre las mujeres, el 63,8\% de las migrantes limítrofes estaba ocupado en el servicio doméstico frente al 40,4\% de las internas. ${ }^{17}$

Aun cuando se observa una continuidad histórica en la proporción de asalariados en ambos grupos, es claro que en el decenio de 1990 los puestos asalariados en los sectores económicos típicos de construcción y servicio doméstico quedaron para los migrantes limítrofes ( $77 \%$ y $51 \%$, respectivamente). En el caso

CUADRO 10

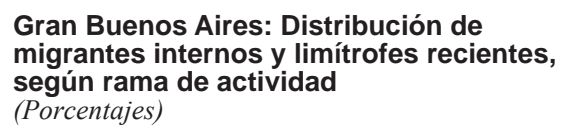

Gran Buenos Aires: Distribución de migrantes internos y limítrofes recientes, según rama de actividad (Porcentajes)

\begin{tabular}{llccr}
\hline Sexo & \multirow{2}{*}{ Rama } & \multicolumn{2}{c}{ Migrantes } & \multirow{2}{*}{ Total } \\
\cline { 3 - 4 } & & Internos & Limítrofes & \\
\hline \multirow{2}{*}{ Varones } & Manufactura & 27,3 & 28,5 & 27,8 \\
& Construcción & 10,7 & 36,4 & 19,2 \\
& Resto & 62,0 & 35,1 & 53,0 \\
& Total & 100,0 & 100,0 & 100,0 \\
\hline \multirow{2}{*}{ Mujeres } & Manufactura & 10,8 & 12,0 & 11,3 \\
& Serv. doméstico & 40,4 & 63,8 & 50,7 \\
& Resto & 48,8 & 24,2 & 38,0 \\
& Total & 100,0 & 100,0 & 100,0 \\
\hline
\end{tabular}

Fuente: Datos mancomunados de la Encuesta Permanente de Hogares (EPH) correspondientes a registros de octubre, Gran Buenos Aires, años 1993, 1995, 1997, 1999 y 2001.

${ }^{17}$ Sobre la base de los datos mancomunados, en el período $1993-$ 2001 la proporción de migrantes limítrofes recientes entre los ocupados era del orden del $2,4 \%$ y la de migrantes internos recientes del orden del 2,6\%. Dada la histórica sobrerrepresentación de estos grupos en la construcción y el servicio doméstico procede introducir la comparación sectorial. El 45\% de los ocupados en servicio doméstico eran migrantes internos, el $13 \%$ eran migrantes limítrofes y el $41 \%$ eran no migrantes; pero al restringir la comparación al grupo de migrantes recientes (hasta 10 años), la proporción de limítrofes asciende al $48 \%$ y la de migrantes internos al $40 \%$. En la construcción, los migrantes internos representan el $35 \%$ de los ocupados, los no migrantes el $47 \%$ y los limítrofes el 16\%; nuevamente, si se considera la composición de los ocupados con residencia de hasta 10 años, los limítrofes trepan al $49 \%$, los internos al $29 \%$ y los no migrantes (nacidos en la provincia de Buenos Aires que se trasladan al área metropolitana de Buenos Aires) representan el 21\%. Fuente: datos mancomunados de la Encuesta Permanente de Hogares (EPH). de las mujeres en el servicio doméstico se da la misma tendencia y los porcentajes de asalariadas son respectivamente del $84 \%$ y $76 \%$.

CUADRO 11

Gran Buenos Aires: Composición de los asalariados migrantes recientes, según origen migratorio, 1993 y 2001 (Porcentajes)

\begin{tabular}{lccr}
\hline Asalariados & Internos & Limítrofes & Total \\
\hline 1993 & 64,6 & 35,4 & 100 \\
2001 & 61,6 & 38,4 & 100 \\
\hline
\end{tabular}

Fuente: Elaboración propia sobre datos de la Encuesta Permanente de Hogares (ЕРH), registros de octubre, Gran Buenos Aires.

CUADRO 12

Gran Buenos Aires: Composición de los migrantes recientes, según origen y por categoría ocupacional, en dos ramas de actividad

(Porcentajes)

\begin{tabular}{llrrr}
\hline Rama & $\begin{array}{l}\text { Categoría } \\
\text { ocupacional }\end{array}$ & \multicolumn{2}{c}{ Migrantes } & \multirow{2}{*}{ Total } \\
\cline { 3 - 4 } Construcción & Internos & limítrofes & \\
& Patrón & 2,2 & & 0,8 \\
& Cuenta propia & 46,5 & 22,8 & 31,6 \\
& Asalariado & 51,3 & 77,2 & 67,6 \\
& Total & 100,0 & 100,0 & 100,0 \\
\hline \multirow{2}{*}{ Servicio doméstico } & Cuenta propia & 23,8 & 16,1 & 19,5 \\
& Asalariado & 76,2 & 83,9 & 80,5 \\
& Total & 100,0 & 100,0 & 100,0 \\
\hline
\end{tabular}

Fuente: Datos mancomunados de la Encuesta Permanente de Hogares (EPH) correspondientes a registros de octubre, Gran Buenos Aires, años 1993, 1995, 1997, 1999 y 2001.

La incidencia de la precariedad laboral -el trabajo no registrado- fue superior entre los limítrofes: solamente el $26 \%$ de los asalariados limítrofes trabajaba en empleos protegidos, el 60,2\% no estaba registrado,

CUADRO 13

Gran Buenos Aires: Beneficios laborales de los asalariados, según su condición migratoria

(Porcentajes)

\begin{tabular}{lccr}
\hline Protección laboral & \multicolumn{2}{c}{ Asalariados } & \multirow{2}{*}{ Total } \\
\cline { 2 - 3 } & $\begin{array}{c}\text { Migrante } \\
\text { interno reciente }\end{array}$ & $\begin{array}{c}\text { Migrante } \\
\text { limítrofe reciente }\end{array}$ \\
\hline Todos los beneficios & 55,3 & 26,1 & 44,5 \\
Sin beneficios & 31,9 & 60,2 & 42,3 \\
Algún beneficio & 12,8 & 13,7 & 13,2 \\
Total & 100,0 & 100,0 & 100,0 \\
\hline
\end{tabular}

Fuente: Datos mancomunados de la Encuesta Permanente de Hogares (EPH) correspondientes a registros de octubre, Gran Buenos Aires, años 1993, 1995, 1997, 1999 y 2001. 
y el resto accedía a algún beneficio; entre los internos, en cambio, los estándares de protección eran bajos pero algo superiores a los de los limítrofes (Cuadro 13).

\section{Nivel educativo e ingresos}

Las diferencias de nivel educativo entre migrantes limítrofes e internos no se evidencian en el conjunto de los ocupados, sino en los ocupados en el servicio doméstico y la construcción. En las mujeres ocupadas en el servicio doméstico, la proporción que había terminado la educación secundaria era más alta entre las migrantes limítrofes que entre las migrantes internas. En los varones que trabajaban en la construcción, el nivel educativo de los migrantes desde las provincias era más bajo que el de los limítrofes, si bien la diferencia

CUADRO 14

Gran Buenos Aires: Composición de los migrantes ocupados, totales y en dos ramas de actividad, según su nivel educativo (Porcentajes)

\begin{tabular}{|c|c|c|c|c|}
\hline & \multirow[t]{2}{*}{ Nivel educativo } & \multicolumn{2}{|c|}{ Migrantes } & \multirow[t]{2}{*}{ Total } \\
\hline & & Internos & limítrofes & \\
\hline \multirow[t]{2}{*}{ Ocupados, total } & $\begin{array}{l}\text { Secundario completo } \\
\text { Secundario incompleto }\end{array}$ & $\begin{array}{l}34,6 \\
65,4\end{array}$ & $\begin{array}{l}34,6 \\
65,4\end{array}$ & $\begin{array}{l}34,6 \\
65,4\end{array}$ \\
\hline & Total & 100,0 & 100,0 & 100,0 \\
\hline \multirow[t]{2}{*}{ Ocupados, varones } & $\begin{array}{l}\text { Secundario completo } \\
\text { Secundario incompleto }\end{array}$ & $\begin{array}{l}32,3 \\
67,7\end{array}$ & $\begin{array}{l}30,5 \\
69,5\end{array}$ & $\begin{array}{l}31,7 \\
68,3\end{array}$ \\
\hline & Total & 100,0 & 100,0 & 100,0 \\
\hline \multirow[t]{2}{*}{ Ocupados, mujeres } & $\begin{array}{l}\text { Secundario completo } \\
\text { Secundario incompleto }\end{array}$ & $\begin{array}{l}38,5 \\
61,5\end{array}$ & $\begin{array}{l}39,1 \\
60,9\end{array}$ & $\begin{array}{l}38,7 \\
61,3\end{array}$ \\
\hline & Total & 100,0 & 100,0 & 100,0 \\
\hline \multirow[t]{2}{*}{ Servicio doméstico, total } & $\begin{array}{l}\text { Secundario completo } \\
\text { Secundario incompleto }\end{array}$ & $\begin{array}{r}8,9 \\
91,1\end{array}$ & $\begin{array}{l}34,6 \\
65,4\end{array}$ & $\begin{array}{l}23,1 \\
76,9\end{array}$ \\
\hline & Total & 100,0 & 100,0 & 100,0 \\
\hline \multirow[t]{2}{*}{ Construcción, total } & $\begin{array}{l}\text { Secundario completo } \\
\text { Secundario incompleto }\end{array}$ & 100,0 & $\begin{array}{l}10,1 \\
89,9\end{array}$ & $\begin{array}{r}6,4 \\
93,6\end{array}$ \\
\hline & Total & 100,0 & 100,0 & 100,0 \\
\hline
\end{tabular}

Fuente: Datos mancomunados de la Encuesta Permanente de Hogares (EPH) correspondientes a registros de octubre, Gran Buenos Aires, años 1993, 1995, 1997, 1999 y 2001.

CUADRO 15

Gran Buenos Aires: Estructura del nivel educativo de los ocupados migrantes recientes, según lugar de origen

(Porcentajes)

\begin{tabular}{|c|c|c|c|c|c|}
\hline Nivel educativo & Bolivia & Paraguay & Perú & Uruguay & Total \\
\hline Sin secundario completo & 70,8 & 88,7 & 21,1 & 64,3 & 65 \\
\hline Con secundario completo & 29,2 & 11,3 & 78,9 & 35,7 & 35 \\
\hline Total & 100,0 & 100,0 & 100,0 & 100,0 & 100 \\
\hline
\end{tabular}

\begin{tabular}{lcccccr}
\hline Nivel educativo & Corrientes & Chaco & Entre Ríos & Santiago & Tucumán & Total \\
\hline Sin secundario completo & 67,6 & 79,6 & 56,8 & 87,6 & 82,8 & 70 \\
Con secundario completo & 32,4 & 20,4 & 43,2 & 12,4 & 17,2 & 30 \\
Total & 100,0 & 100,0 & 100,0 & 100,0 & 100,0 & 100 \\
\hline
\end{tabular}

Fuente: Datos mancomunados de la Encuesta Permanente de Hogares (EPH) correspondientes a registros de octubre, Gran Buenos Aires, años 1993, 1995, 1997, 1999 y 2001. 
entre ambos los dos segmentos era menos marcada que entre las mujeres (cuadro 14).

Los migrantes limítrofes mantuvieron en el decenio de 1990 características similares a las que exhibían en las dos décadas anteriores y que compartían con los migrantes internos: niveles bajos de educación y calificación. El cambio que trajo la década de 1990 fue el de hacer visible el deterioro de los niveles educativos de los migrantes internos respecto de aquellos de los limítrofes.

Los migrantes internos provenían mayoritariamente de provincias en las que los niveles de deserción, repitencia y edades altas en la enseñanza secundaria eran claramente mayores que en las demás, y sobre todo que en el área metropolitana. Más que un mejoramiento de los niveles de calificación de los limítrofes, lo que se manifestó fue el descenso relativo de la formación de los migrantes nativos que llegaron al Gran Buenos Aires a partir de la década de 1980 (datos de la Red Federal de Educación del Ministerio de Educación).

En parte, los migrantes limítrofes estaban en condiciones más favorables para ser requeridos por las ramas de actividad en que tradicionalmente se insertaban los trabajadores migrantes recientes: la construcción y el servicio doméstico. Con niveles de educación comparables y en algunos casos superiores, y dispuestos a aceptar salarios y condiciones de trabajo más flexibles, fueron más demandados que sus pares migrantes internos. Esta es una explicación posible del impacto diferencial de la crisis en los migrantes limítrofes y en los internos.

A lo largo del período considerado, los limítrofes trabajaron en condiciones más desventajosas. Sus ingresos mensuales se mantuvieron por debajo de los percibidos por los migrantes internos, asalariados y no asalariados, y sus jornadas de trabajo eran más largas (cuadro 16). La cantidad de horas trabajadas por los limítrofes fue creciendo, incluso mientras caía la demanda de trabajo; en cambio, disminuían las horas trabajadas por los migrantes internos, sobre todo en la construcción y el servicio doméstico, lo que reflejaba la caída de la demanda por ese segmento. Los ingresos reales de los migrantes limítrofes quedaron por debajo del promedio general y del de los internos (gráficos 1 y 2).

Gran Buenos Aires: Coeficientes del ingreso horario, ingreso mensual y horas trabajadas de los migrantes limítrofes recientes respecto de los correspondientes a los migrantes internos recientes

\begin{tabular}{|c|c|c|c|c|c|c|c|c|c|c|}
\hline Migrantes limítrofes & Condiciones laborales & 1993 & 1994 & 1995 & 1996 & 1997 & 1998 & 1999 & 2000 & 2001 \\
\hline \multirow[t]{3}{*}{ Totales } & Ingreso horario & 0,86 & 0,80 & 0,69 & 0,77 & 0,77 & 0,91 & 0,70 & 0,81 & 0,77 \\
\hline & Ingreso mensual & 0,89 & 0,80 & 0,77 & 0,74 & 0,91 & 0,91 & 0,72 & 0,90 & 0,81 \\
\hline & Horas trabajadas & 1,02 & 1,00 & 1,06 & 0,93 & 1,14 & 1,00 & 1,07 & 1,06 & 1,10 \\
\hline \multirow[t]{3}{*}{ Asalariados } & Ingreso horario & 0,85 & 0,85 & 0,70 & 0,83 & 0,73 & 0,93 & 0,72 & 0,85 & 0,77 \\
\hline & Ingreso mensual & 0,89 & 0,79 & 0,77 & 0,73 & 0,89 & 0,91 & 0,78 & 0,89 & 0,83 \\
\hline & Horas trabajadas & 1,04 & 0,96 & 1,04 & 0,93 & 1,17 & 0,98 & 1,15 & 1,05 & 1,11 \\
\hline
\end{tabular}

Fuente: Encuesta Permanente de Hogares, registros de octubre, Gran Buenos Aires.

GRAFICO 1

Evolución del ingreso del horario real de asalariados según condición migratoria interna o limítrofe $(1993=100)$

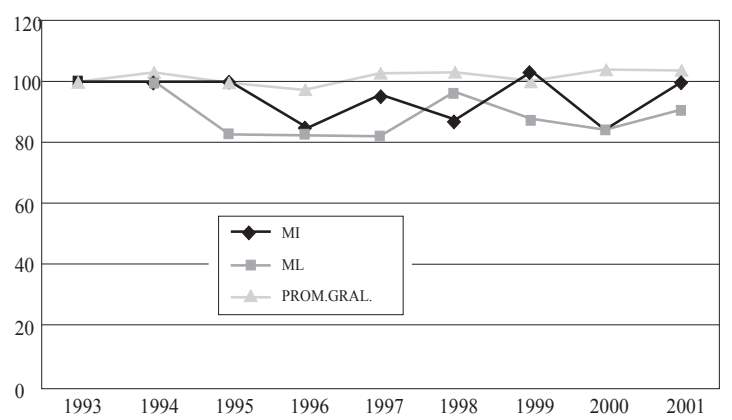

Fuente: Encuesta Permanente de Hogares (EPH), registros de octubre, Gran Buenos Aires.
GRAFICO 2

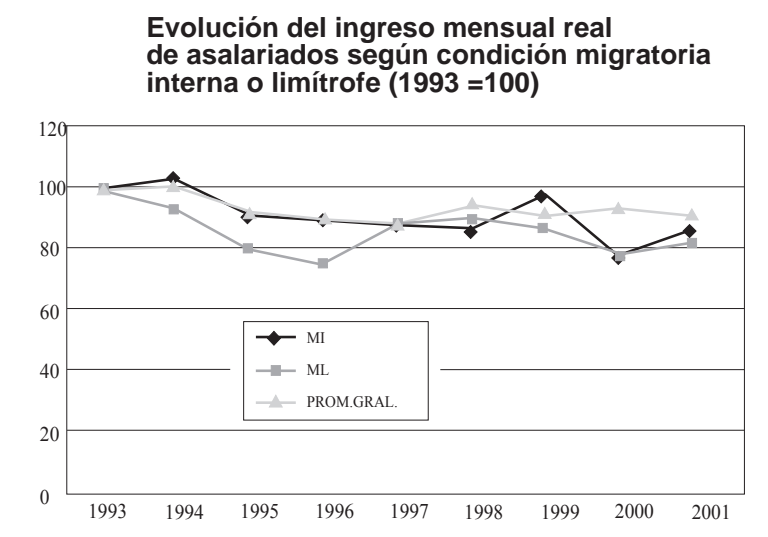

Fuente: Encuesta Permanente de Hogares (EPH), registros de octubre, Gran Buenos Aires. 


\section{IV}

\section{Conclusiones}

Las transformaciones económicas y del mercado de trabajo que se dieron en década de 1990 afectaron los ritmos migratorios al Gran Buenos Aires; a lo largo de toda la década perduró la migración limítrofe y tendió a disminuir la migración interna. La hipótesis de que habría tenido lugar un efecto de retorno o retiro de la migración interna, empujada por la caída de la demanda de trabajo, merece ser investigada.

Los cambios en la inserción laboral de los migrantes internos estuvieron inducidos por la demanda laboral, que, sobre todo en la construcción y el servicio doméstico, privilegió la incorporación de segmentos de la fuerza de trabajo con menores exigencias de protección, en puestos de trabajo precarios, en condiciones de trabajo desfavorables y con salarios bajos. Como había habido cambios en la composición de la oferta - un leve mejoramiento del nivel educativo de los migrantes limítrofes respecto del nivel de los migrantes internos- la demanda se reorientó hacia los primeros. En la literatura sobre migraciones en el caso argentino, diversos autores han hecho hincapié en una explicación basada en la oferta: así, la hipótesis que sostiene que no habría existido competencia entre migrantes limítrofes y migrantes internos, se refiere sobre todo a las décadas previas a la de 1990, y plantea que los nativos no estuvieron dispuestos a aceptar esos puestos de trabajo. Llegado el decenio de 1990, argumentan, la expansión del desempleo en el área metropolitana y la destrucción de empleos podría provocar competencia entre ambos grupos de trabajadores. Sin embargo, no parece claramente desarrollado el análisis del papel de la demanda en la competencia entre esos dos segmentos migrantes. El presente trabajo concluye que el factor con más peso ha sido la reorientación de la demanda de trabajo, dados los cambios en la composición de los flujos migratorios: el aumento del nivel educativo de los migrantes limítrofes y el descenso del de los internos. Este proceso llevó al desplazamiento de los migrantes internos recientes en los sectores típicos de inserción de migrantes; cayó la tasa de actividad de los migrantes internos, lo que sería un indicador de desaliento, mientras que aumentó la actividad de los limítrofes, aunque el desempleo afectó a ambos grupos. Los limítrofes que permanecieron ocupados ingresaron en puestos con jornadas laborales extensas y bajas remuneraciones horarias. En la construcción cayó el empleo, y en el servicio doméstico la caída fue menor, pero en ambos sectores se elevó la proporción de migrantes limítrofes.

La expansión del desempleo desde mediados de la década de 1980 seguramente ha incidido en la conformación de un núcleo persistente de desocupados que no han podido reinsertarse en los sucesivos períodos de reactivación económica. Sin embargo, en los diagnósticos sobre la situación social del área metropolitana a menudo se ha minimizado el volumen y la extensión de este núcleo de desempleo y, por lo tanto, de pobreza estructural.

Nuestro argumento -que requiere una investigación más detallada- sugiere que las transformaciones señaladas incidieron sobre la composición de este sector de pobreza y desempleo estructurales. En los decenios de 1970 y 1980, la pobreza estructural estuvo más ligada a ambos sectores de migrantes -internos y limítrofessi bien con mayor incidencia de la pobreza entre los limítrofes. En cambio, en la década de 1990 la extensión del desempleo y la persistencia de la pobreza se circunscribieron más claramente al conjunto de los migrantes internos. Los migrantes internos serían los más proclives a sufrir situaciones de fuerte privación social, iniciando un descenso hacia la exclusión. Este no es un proceso reciente, sino un nuevo patrón de distribución del acceso a actividades generadoras de ingresos, que facilitó el ciclo de reproducción de la "trampa de la pobreza". La sustitución de segmentos desfavorecidos en el mercado de trabajo aleja de quienes fueron desplazados las posibilidades de inserción laboral $\mathrm{y}$, en general, de obtención de ingresos.

Estos procesos han estado configurando un nuevo escenario social, con divisiones cada vez más pronunciadas entre los ocupantes de empleos precarios y los desocupados "no elegibles". 


\section{Apéndice}

Características de la Encuesta Permanente de Hogares (ЕPH) que efectúa el INDEC

Esta encuesta se desarrolla sobre la base de un conjunto de muestras de los principales aglomerados urbanos del país, que representan aproximadamente el 70\% de la población nacional urbana. La población del Gran Buenos Aires, que abarca la Ciudad de Buenos Aires y 19 partidos del conurbano bonaerense, alberga el 30\% de la población total del país y aproximadamente el $40 \%$ de la población urbana total. La recopilación de datos se realiza dos veces al año, durante los meses de mayo y octubre, y las unidades de observación son los hogares. La muestra de hogares del Gran Buenos Aires es representativa del $100 \%$ de la población del aglomerado. La información que se recolecta corresponde a características de los hogares y de los individuos. Entre las primeras cabe destacar el tamaño y composición del hogar y las características de la vivienda; entre las segundas se encuentran variables demográficas, laborales, de ingresos, educacionales y de migración.

\section{Mancomunación de registros}

La estrategia metodológica elegida para esta parte del estudio, consistente en constituir un conjunto mancomunado de registros, permite realizar tabulados a un nivel de desagregación mayor que el usual para el trabajo basado en los registros que se obtienen por separado en cada recopilación de datos realizada por la EPH (es decir, en cada "onda" de datos), sin que los resultados pierdan significación. El supuesto sobre el que se asienta la utilización de este procedimiento es que la década de 1990 fue homogénea en materia de incentivos y desincentivos, y que los cambios que hubieran podido ocurrir en cada período son de pequeña magnitud y, por lo tanto, no modifican el balance final. La mancomunación de datos se realizó con los registros de octubre de 1993, 1995, 1997, 1999 y 2001, teniendo en cuenta que entre uno y otro de ellos se produjo la rotación completa de los hogares que responden, evitando la superposición de registros correspondientes a los mismos individuos.

CUADRO A.

Gran Buenos Aires: Composición de los migrantes recientes residentes, según lugar de origen

(Porcentajes)

\begin{tabular}{|c|c|c|c|c|}
\hline \multirow[b]{2}{*}{ Provincia o país } & \multicolumn{2}{|c|}{ Octubre de 1993} & \multicolumn{2}{|c|}{ Octubre de 2000} \\
\hline & $\begin{array}{l}\text { Migrante interno } \\
\text { reciente }\end{array}$ & $\begin{array}{l}\text { Migrante limítrofe } \\
\text { reciente }\end{array}$ & $\begin{array}{l}\text { Migrante interno } \\
\text { reciente }\end{array}$ & $\begin{array}{l}\text { Migrante limítrofe } \\
\text { reciente }\end{array}$ \\
\hline Corrientes & 13,6 & & 8,4 & \\
\hline Chaco & 16,2 & & 9,2 & \\
\hline Entre Ríos & 6,9 & & 7,5 & \\
\hline Santiago & 11,0 & & 9,9 & \\
\hline Tucumán & 7,7 & & 7,8 & \\
\hline Misiones & 11,4 & & 21,7 & \\
\hline Resto provincias & 33,2 & & 35,5 & \\
\hline Total migrantes de provincias & 100,0 & & 100,0 & \\
\hline Bolivia & & 15,5 & & 16,5 \\
\hline Paraguay & & 42,6 & & 42,4 \\
\hline Perú & & 5,7 & & 27,4 \\
\hline Uruguay & & 27,2 & & 7,4 \\
\hline Resto & & 9,0 & & 6,3 \\
\hline Total migrantes limítrofes & & 100,0 & & 100,0 \\
\hline
\end{tabular}

Fuente: Encuesta Permanente de Hogares (EPH). 
GRAFICO A.1

Gran Buenos Aires: Evolución de la población ocupada, según su condición de migración

(Indice 1993=100)

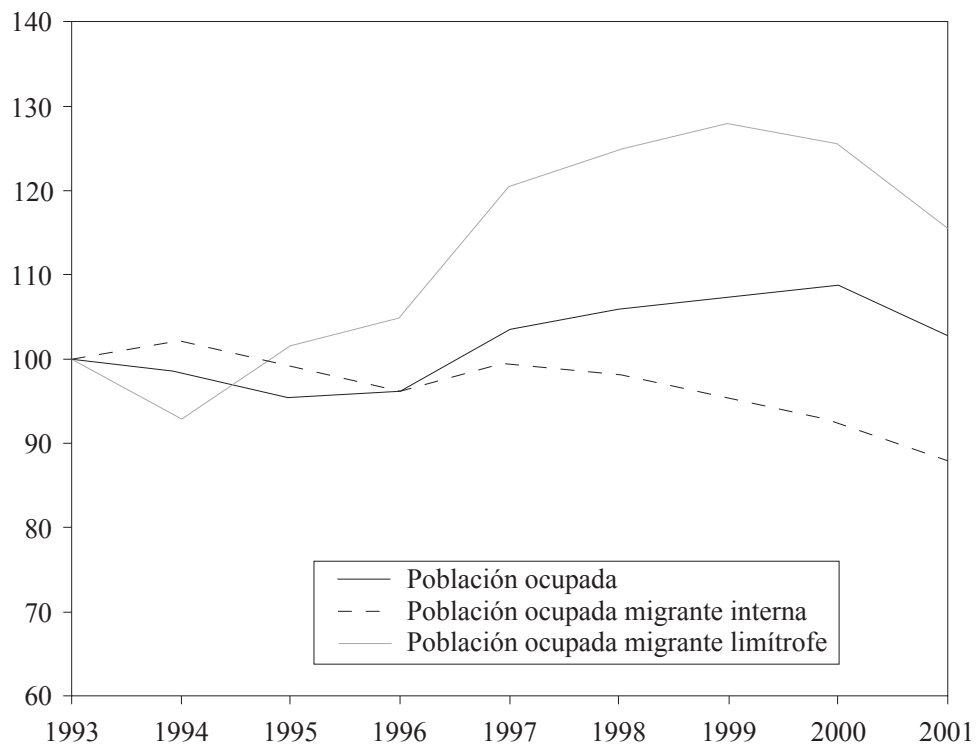

Fuente: Encuesta Permanente de Hogares (EPH), registros de octubre, Gran Buenos Aires.

GRAFICO A.2

Gran Buenos Aires: Intervalos de confianza al $90 \%$ de tasas de desocupación abierta de migrantes limítrofes e internos, varones

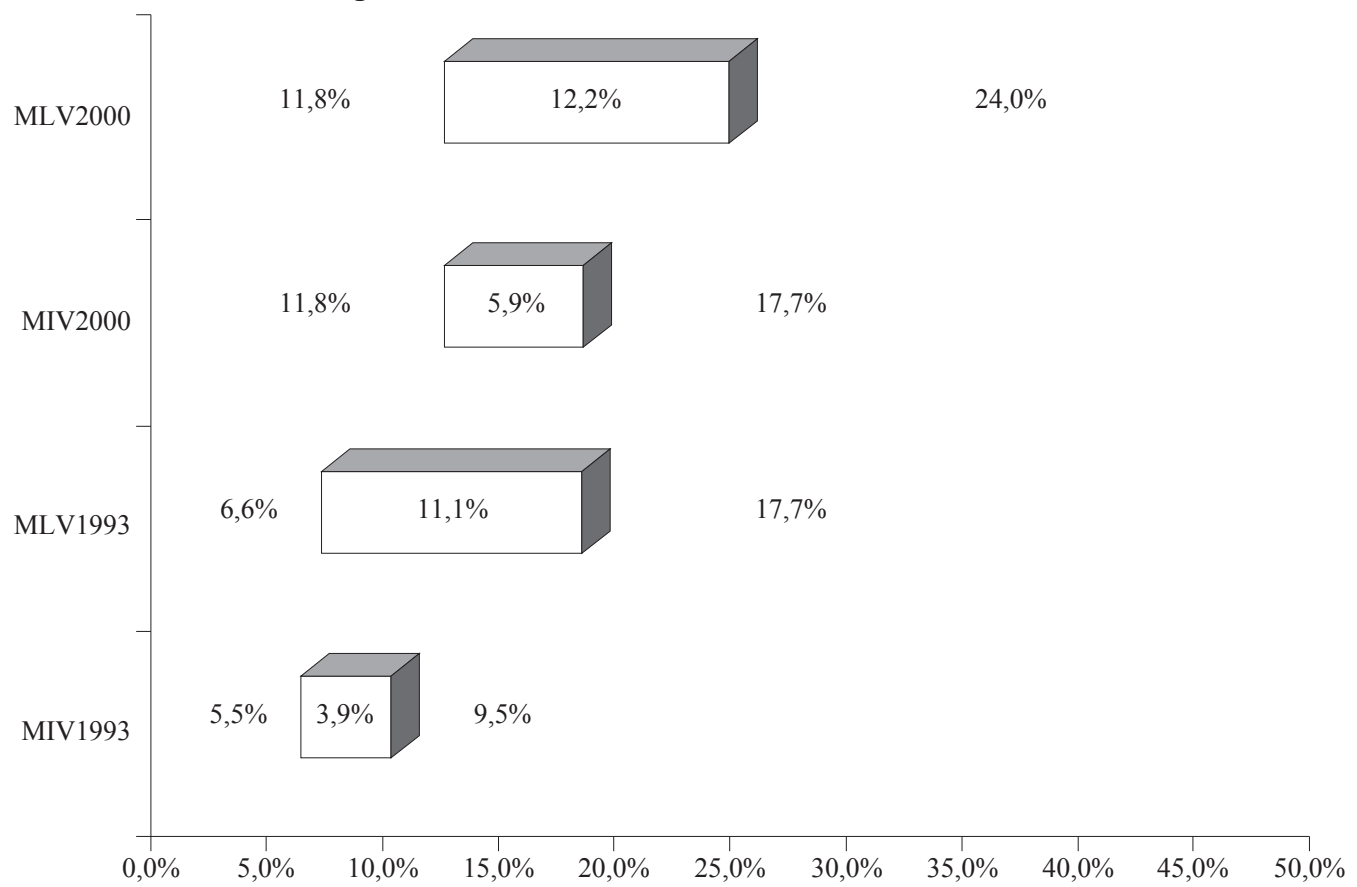

Fuente: Encuesta Permanente de Hogares (EPH), registros de Octubre, Gran Buenos Aires.

${ }^{a}$ MLV= Migrantes limítrofes varones. MIV= Migrantes internos varones. 
Gran Buenos Aires: Intervalos de confianza al $90 \%$ de tasas de desocupación abierta de migrantes limítrofes e internos, mujeres ${ }^{a}$

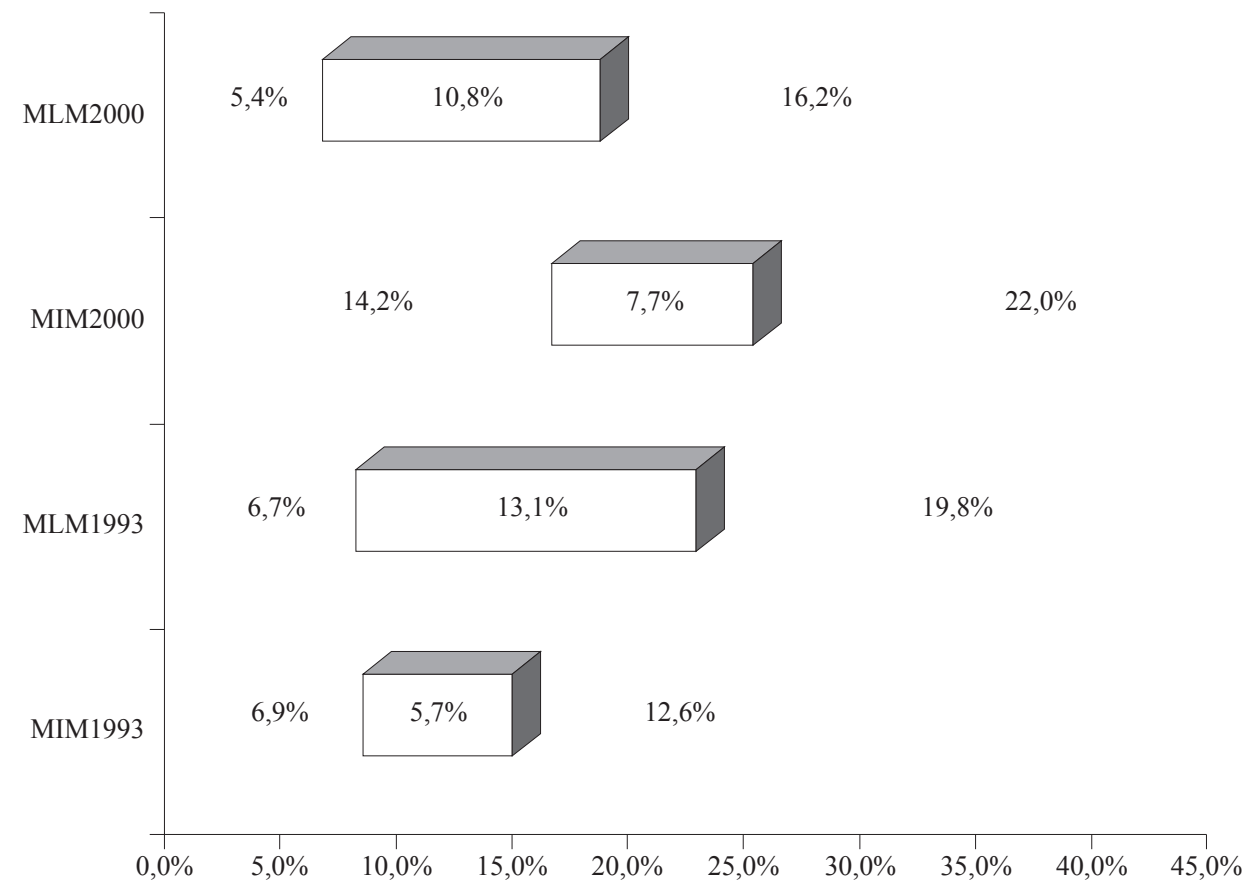

Fuente: Encuesta Permanente de Hogares (EPH), registros de Octubre, Gran Buenos Aires.

a $\mathrm{MLM}=$ Migrantes limítrofes mujeres. MIM= Migrantes internas mujeres.

CUADRO A.2

Gran Buenos Aires: Análisis de regresión lineal por mínimos cuadrados ordinarios ${ }^{a}$

Variable independiente: Participación de migrantes limítrofes recientes en la población económicamente activa (PEA)

Variables dependientes:

(1) Tasa de empleo de migrantes internos recientes jóvenes sin secundario completo

(2) Tasa de empleo de migrantes internos antiguos jóvenes sin secundario completo

(3) Tasa de empleo de migrantes limitrofes recientes jóvenes sin secundario completo

(4) Tasa de empleo de no migrantes mayores sin secundario completo

(5) Tasa de actividad de no migrantes jóvenes sin secundario completo

(6) Tasa de actividad de migrantes limitrofes jóvenes sin secundario completo

(7) Tasa de actividad de migrantes limitrofes antiguos mayores sin secundario completo

\begin{tabular}{|c|c|c|c|c|c|c|c|}
\hline $\begin{array}{l}\text { Variable } \\
\text { independiente }\end{array}$ & $\begin{array}{c}\text { Variable } \\
\text { dependiente } \\
\text { (1) }\end{array}$ & $\begin{array}{c}\text { Variable } \\
\text { dependiente } \\
\text { (2) }\end{array}$ & $\begin{array}{c}\text { Variable } \\
\text { dependiente } \\
\text { (3) }\end{array}$ & $\begin{array}{c}\text { Variable } \\
\text { dependiente } \\
\text { (4) }\end{array}$ & $\begin{array}{c}\text { Variable } \\
\text { dependiente } \\
\text { (5) }\end{array}$ & $\begin{array}{c}\text { Variable } \\
\text { dependiente } \\
(6)\end{array}$ & $\begin{array}{c}\text { Variable } \\
\text { dependiente } \\
(7)\end{array}$ \\
\hline $\begin{array}{l}\text { Participación de migrantes } \\
\text { limítrofes recientes en la PEA }\end{array}$ & $\begin{array}{r}-13,537 \\
(7,942)\end{array}$ & $\begin{array}{l}11,241 \\
(6,378)^{b}\end{array}$ & $\begin{array}{l}-21,103 \\
(10,167)^{b}\end{array}$ & $\begin{array}{c}4,654 \\
(2,229)^{b}\end{array}$ & $\begin{array}{l}-9,867 \\
(3,885)^{c}\end{array}$ & $\begin{array}{r}-17,181 \\
(8,030)^{\mathrm{c}}\end{array}$ & $\begin{array}{l}13,106 \\
(5,523)^{\mathrm{c}}\end{array}$ \\
\hline $\mathrm{R}^{2}$ & 0,154 & 0,163 & 0,212 & 0,214 & 0,287 & 0,222 & 0,260 \\
\hline
\end{tabular}

$\mathrm{N}^{\mathrm{o}}$ de observaciones: 18

Fuente: Elaboración propia sobre datos de los registros de mayo y octubre entre octubre de 1993 y mayo de 2002, Gran Buenos Aires.

a Las cifras entre paréntesis corresponden a error estándar. Los tramos de edad se definieron así: jóvenes (entre 16 y 29 años); adultos (entre 30 y 44) y mayores (más de 45 años).

b Significativo al $10 \%$

c Significativo al $5 \%$. 
CUADRO A.3

Gran Buenos Aires: Análisis de regresión lineal por mínimos cuadrados ordinarios ${ }^{\mathrm{a}}$ Variable independiente: Tasa de participación de migrantes limitrofes recientes en la población ocupada

Variables dependientes:

(1) Tasa de empleo de migrantes internos recientes jóvenes sin secundario completo

(2) Tasa de empleo de migrantes internos antiguos jóvenes sin secundario completo

(3) Tasa de empleo de migrantes internos antiguos adultos sin secundario completo

(4) Tasa de empleo de no migrantes mayores sin secundario completo

(5) Tasa de actividad de migrantes limitrofes recientes jóvenes sin secundario completo

\begin{tabular}{lccccc}
\hline $\begin{array}{l}\text { Variable } \\
\text { independiente }\end{array}$ & $\begin{array}{c}\text { Variable } \\
\text { dependiente } \\
(1)\end{array}$ & $\begin{array}{c}\text { Variable } \\
\text { dependiente } \\
(2)\end{array}$ & $\begin{array}{c}\text { Variable } \\
\text { dependiente } \\
(3)\end{array}$ & $\begin{array}{c}\text { Variable } \\
\text { dependiente } \\
(4)\end{array}$ & $\begin{array}{c}\text { Variable } \\
\text { dependiente } \\
(5)\end{array}$ \\
\hline $\begin{array}{l}\text { Porcentaje de migrantes limítrofes } \\
\text { recientes en el total de ocupados }\end{array}$ & $\begin{array}{c}-11,170 \\
(7,861)\end{array}$ & $\begin{array}{c}11,988 \\
(6,031)^{\mathrm{b}}\end{array}$ & $\begin{array}{c}7,299 \\
(4,285)\end{array}$ & $\begin{array}{c}3,911 \\
(2,224)^{\mathrm{b}}\end{array}$ & $\begin{array}{c}-18,648 \\
(7,463)^{\mathrm{c}}\end{array}$ \\
\hline $\mathrm{R}^{2}$ & 0,112 & 0,198 & 0,154 & 0,162 & 0,281 \\
\hline
\end{tabular}

$\mathrm{N}^{\mathrm{o}}$ de observaciones: 18

Fuente: Elaboración propia sobre datos de registros de mayo y octubre, entre octubre de 1993 y mayo de 2002, Gran Buenos Aires.

a Las cifras entre paréntesis corresponden a error estándar. Los tramos de edad se definieron así: jóvenes (entre 16 y 29 años); adultos (entre 30 y 44) y mayores (más de 45 años).

b Significativo al $10 \%$.

c Sifnificativo al $5 \%$.

Las migraciones provenientes de países limítrofes han representado tradicionalmente una proporción baja de la población total: 2,4\% hasta 1980 y 2,5\% en 1991 . El flujo migratorio limítrofe, que había crecido en la primera mitad del decenio de 1970 , se desaceleró entre 1975 y 1980.

El crecimiento de la población total en Argentina ha seguido una tendencia decreciente: las tasas anuales medias en los decenios de 1970, 1980 y 1990 alcanzaron a $1,8 \%, 1,6 \%$ y $1 \%$, respectivamente (INDEC, censo de 1970,1980 y 1991). ${ }^{18} \mathrm{Al}$ disminuir las migraciones internacionales no limítrofes, aumentó la proporción de migrantes limítrofes en el total de migrantes, llegando al 52\% en 1991 (INDEC, 1991).

\footnotetext{
18 Para el período 1991-2001 se ha estimado la tasa de variación
} según los datos preliminares del Censo Nacional de Población 2001. 
Benencia, R. (2000): Argentina: la problemática social de la migración limítrofe, Comercio exterior, vol. 50, $\mathrm{N}^{\circ} 3$, México, D.F., Banco Nacional de Comercio Exterior (BANCOMEXT).

Benencia, R. y A. Gazotti (1995): Migración limítrofe y empleo: precisiones e interrogantes, Estudios migratorios latinoamericanos, año 10, $\mathrm{N}^{\circ} 31$, Buenos Aires, Centro de Estudios Migratorios Latinoamericanos (CEMLA).

CELADE (1998): América Latina: proyecciones de población, 1970-2050, Boletín demográfico, $\mathrm{N}^{\circ}$ 62, LC/DEM/G.180, Santiago de Chile.

CELS (Centro de Estudios Legales y Sociales) (1998): Informe anual, Buenos Aires.

(2000): Informe anual, Buenos Aires. Cortés, R. (1985): Cambios en el mercado de trabajo urbano en la Argentina: 1974 -1983, serie Documentos e informes de investigación, $N^{\circ} 14$, Buenos Aires, Facultad Latinoamericana de Ciencias Sociales (FLACSO).

INDEC (Instituto Nacional de Estadística y Censos) (1980): Censo Nacional de Población, 1980, Buenos Aires. (1991): Censo Nacional de Población, 1991, Buenos Aires. Aires.

(varios años): Encuesta Permanente de Hogares, Buenos

Lattes, A. (1997): La dinámica demográfica y la migración en la evolución reciente de la actividad económica en el Area Metropolitana de Buenos Aires, Buenos Aires, inédito.

Maguid, A. (1990): Argentina: migración y pobreza durante la década del 80, Buenos Aires, Consejo Nacional de Investigaciones Científicas y Técnicas (CONICET). (1995): Migrantes limítrofes en Argentina: su inserción e impacto en el mercado de trabajo, Estudios del trabajo, $\mathrm{N}^{\circ}$ 10, Buenos Aires, Asociación Argentina de Especialistas en Estudios del Trabajo (ASET).
(2001): El chivo expiatorio. Problemas de empleo, Encrucijadas, año 1, $\mathrm{N}^{\circ}$ 7, Buenos Aires, Universidad de Buenos Aires.

Mármora, L. (1977): Política e investigación en el proceso de planificación migratoria, Santiago de Chile, Programa de Investigaciones Sociales sobre Población en América Latina (PISPAL)/División de Población (CELADE).

(1994): Desarrollo sostenido y políticas migratorias: su tratamiento en los espacios latinoamericanos de integración, Revista de la oIM sobre migraciones en América Latina, vol.12, No 1, Santiago de Chile, Centro de Información sobre las Migraciones en América Latina (CIMAL).

Marshall, A. (1977): Inmigración, demanda de fuerza de trabajo y estructura ocupacional en el área metropolitana argentina, Desarrollo económico, vol. 17, $\mathrm{N}^{\circ} 65$, Buenos Aires, Instituto de Desarrollo Económico y Social (IDES). (2000): Política inmigratoria y el mercado de trabajo, Memorias de las IV Jornadas Argentinas de Estudios de Población, Resistencia, Chaco.

Marshall, A. y D. Orlansky (1983): Inmigración de países limítrofes y demanda de mano de obra en la Argentina, 1940-1980, Desarrollo económico, vol. 23, No 89, Buenos Aires, Instituto de Desarrollo Económico y Social (IDES).

Montoya, S. y M. Perticara (1995): Los migrantes de países limítrofes en los mercados de trabajo urbanos, Estudios, № 75, Córdoba, Instituto de Estudios Económicos sobre la Realidad Argentina y Latinoamericana (IEERAL), octubre-diciembre.

Novick, S. (2001): Un país ¿receptor? Políticas migratorias nacionales, Encrucijadas, año 1, № 7, Buenos Aires, Universidad de Buenos Aires. 